Khayal Iskandarov, Piotr Gawliczek (2019) The south Caucasus and NATO'S defence education enhancement programme. Retrospective analysis. Social development \& Security. 9(5), 3 - 14.

DOI: http://doi.org/10.33445/sds.2019.9.5.1

\title{
The south Caucasus and NATO'S defence education enhancement programme. Retrospective analysis
}

\author{
Khayal Iskandarov*, Piotr Gawliczek ** \\ * War College of the Armed Forces, Republic of Azerbaijan \\ e-mail:xayal1333@gmail.com \\ ** University of Warmia and Mazury in Olsztyn, Poland, \\ e-mail:pgawliczek@gmail.com, \\ Ph.D, Assoc. Prof., \\ ADL Coordinator.
}

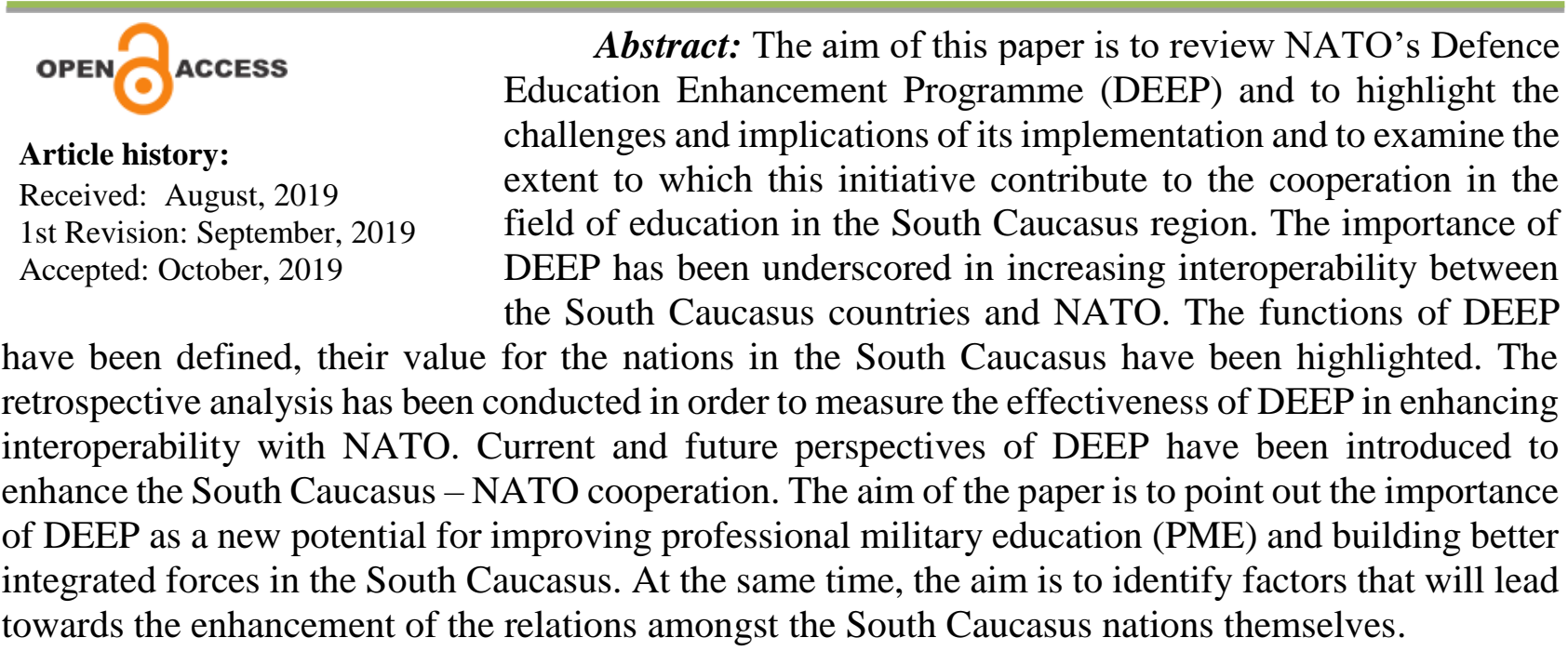

Keywords: NATO, DEEP, South Caucasus, intellectual interoperability, PME.

\section{Introduction}

The collapse of the Soviet Union in 1991 fundamentally altered the geopolitical dynamics of the South Caucasus as each of the new successor states sought to define their own national interests and policy priorities. Another effect of the collapse of the Soviet Union was that it permitted other powers to vie for influence in the former Soviet republics, which they were previously unable to do owing to the presence of a strong hegemonic power of the Russian Empire and later the Soviet Union. While the South Caucasus was previously considered to be on the periphery of the international agenda, after the dissolution of the Soviet Union and the subsequent formation of newly independent states, it became much more important both to its neighbors and influential non-regional actors [10]. Collaborative Security Treaty Organization (CSTO) and 
NATO are interested in the region as a strategically important energy market and a lucrative traffic artery [10].

Russia has been exerting itself in order to incorporate all South Caucasus countries into CSTO due to its geostrategic location and natural resources [10]. However, only Armenia is a member state, Azerbaijan's membership is not plausible, where Georgia's incorporation into this organization is a pipe dream. CSTO struggles to burnish an image of multifunctional organization, presents different initiatives and pits itself against NATO. But CSTO has never been considered an alternative to NATO. The differences between them will continue to grow in the coming years, since the latter has made giant strides during the post-soviet period regarding its partnership policy.

Having adopted a New Strategic Concept in 1991 NATO began to focus on the development of multinational force projection in order to adapt to the post-Cold War era and expand its capabilities for crisis management operations. In pursuit of future strategic goals, NATO had to broaden and deepen cooperation with the countries beyond its traditional borders. Thus, the Alliance was in urgent need of partners those would be able to keep abreast of NATO standards. This approach in turn required member, as well as partner forces to work together for out-of-area operations. The first initiative to invite those nations to cooperation was Partnership for Peace (PfP) programme, which was launched in 1994. The ultimate goal of this programme was and still is to support partners in their efforts to reform their national defence structures and to assist them in developing their national capabilities. This initiative proved to be really successful tool. Shortly afterwards the Alliance embarked upon Partnership Planning and Review Process with the aim of promoting the development of forces and capabilities by partners that are best able to cooperate alongside NATO Allies in crisis response operations and other activities to maintain security and stability. It provides a structured approach for enhancing interoperability and capabilities of partner forces that could be made available to the Alliance for multinational training, exercises and operations. This strategy continued over the ensuing years and the Alliance initiated new programmes and mechanisms (Operation Capabilities Concept, Membership Action Plan, Individual Partnership Action Plan, etc.) for closer and deeper cooperation with its partners. The objective of NATO's partnerships is to safeguard security together, as stated in all three post-Cold War Strategic Concepts [11].

The nations in the South-Caucasus region have been struggling to reach Western standards in every possible field since they got their independence from USSR. Their armed forces were founded in the period of chaos resulting from the collapse of the Soviet Union when all three countries were suffering from wars. Therefore, defence education occupies one the first places among these fields regarding the geopolitical landscape of the region. There are different tools and means to realize the desire to improve their PME. DEEP is one of these productive tools to facilitate their integration into Western structures. Education and training is one of the main domains of cooperation between NATO and partner nations. It is what is motivating NATO to shift its attention from weapons systems to joint, multinational and interagency education and training of those people who more broadly develop and employ the doctrines, strategies and policies that integrate all the instruments of power - political, military, 
economic and informational - to produce leaders better equipped to deal with a range of issues that define the twenty-first-century security environment [13]. NATO has supported the South-Caucasus countries together with other post-Soviet states in reforming their respective security sectors in line with Western standards and bringing them closer to the Alliance.

Even though the paths of the three South Caucasus republics have been different since the end of the Cold War in terms of their geo-political ambitions, with Armenia being a CSTO member, Azerbaijan pursuing an independent policy regarding global powers, and Georgia, apparently, demonstrating a pro-NATO position, all three countries are enthusiastic end users of this programme [10].

Comparative analysis, synthesis, inductive and, deductive methods have been used in the paper to come up with conclusive outcomes and recommendations for the countries in the region.

\section{DEEP as a tool to boost intellectual interoperability with NATO}

Since 1994, NATO has created partnerships as an institutional framework for its relations with countries that cannot or do not want to become Alliance members. In the past 25 years, the circle of countries involved has become ever larger, the associated agenda ever more heterogeneous, and the goals pursued by NATO ever more diverse [12]. The cooperation among the allied and partner states and their military educational facilities is an important factor in attaining interoperability, necessary for dealing with current security challenges. NATO gives the best direction on professional development and education. The Alliance has published a professional military education curriculum for both officers and non-commissioned officers, which are designed as a start point for NATO member nations to develop their own national curriculums, and purport to foster intellectual interoperability and greater professionalism in allied armed forces [17]. Remarkably, the education has been accelerated to levels no one would have ever predicted, as evidenced by the institutional changes that have occurred in Central and Eastern Europe over the last twenty-five years [25]. Thus, NATO's partnership tools provide golden opportunity for the enhancement of the cooperation between NATO and partner countries.

In the current strategic concept (2010), the three core tasks of NATO are collective defence, crisis management and cooperative security. Out of these, cooperative security is very much about partnerships. Thus, cooperative security is a broad task consisting of numerous elements. Generally speaking it consists of three components: strengthening partnerships, contributing to arms control, non-proliferation and disarmament and assisting potential new countries to prepare for NATO membership. An important sub element of both strengthening partnerships and preparing new countries for potential membership is interoperability. In short with the new NATO missions and engagement in operational theatres there has been a dramatic shift from a single nation fighting on its own to coalitions where multinational units, down to the level of platoons, are working together [11].

On the other hand, the mechanisms that support achieving interoperability are: effective implementation of allied agreed standards (STANAGs), doctrine and tactics, 
joint training, participation in NATO/multinational exercises, application of NATO policy related to lessons learned, conduct of demonstrations and tests. According to the NATO Strategic Concept 2010, partnerships with the third countries "can make a concrete contribution to enhancing international security, to defending the values on which the Alliance is based, to NATO's operations and to preparing interested nations for membership of NATO" [10].

The implementation of the Alliance grand strategy requires the continuous improvement of military effectiveness. In this regard, interoperability is a sine qua non for the success of any operation/mission in coalition warfare [11].

According to an action plan approved by NATO Defence ministers, interoperability has three dimensions:

- technical (hardware and systems);

- procedural (doctrine and procedures);

- human (language, terminology and training).

The human dimension is inextricably linked with intellectual interoperability. As NATO allies and PfP partners work together to build defence institutions and develop human capital programs need to be put in place to educate national security professionals in new ways and produce graduates with different skill sets [13]. One of the functional subject areas in which NATO provided support since the mid-2000s, via the International Staff, was that of defence education. Defence education support was designed to address interoperability "of minds" - a set of common references, doctrines and approaches to problem solving that would allow officers from different backgrounds to understand each other [5].

DEEP is an invaluable tool to develop educational institutions in the defence sector and contribute to all dimensions of interoperability. The main goal of the Programme is to enhance the international security throughout professionalization of the officers and civilian employees' education system in the partner states according to the NATO standards [2]. Through faculty development, curriculum development and peer-to-peer consultations, the DEEP Programme fosters defence capacity building, cooperative capability development and standardization, and promotes interoperability of processes and methodologies to enhance democratic institutions [6]. According to Dr. Raphael Perl, PfP Consortium executive director, "what makes DEEPs attractive is implementing a non-cookie-cutter approach to defence education and defence institution building in post-Communist societies and beyond" [18]. The key aspect of DEEP is the connections it facilitates between senior educators from defence education institutions in NATO countries and affiliated institutions. Another key function of DEEP is in helping sustain regional stability through multinational education and research [25]. A successful and effective DEEP requires stakeholders, participating nations and volunteers to balance the short view with the long view. Rapid change is not always sustainable change. A possible indicator of success is to have host nation defence institutions meet their IPAP goals, incorporate reference curriculum methods and sources into their own programs of instructions and adopt learner-centric knowledge delivery methods. The aim is the attainment of the "operational" objectives of the programme; intellectual interoperability, like-mindedness, in short, integration [14]. 
DEEP endeavors through dialogue and encouragement to influence partner educators in the direction of the following objectives [1]:

- guide and mentor reforms in professional and military education, both in individual defence education institutions and in a defence-wide holistic approach to professional military education;

- promote learner-centered education and innovative use of instructional technologies;

- encourage and enable the use of learning objectives which facilitate a depth of learning that can be readily applied through practice and partner experience;

- assist in the development of faculty assessments and action plans to employ these methods in support of partner goals contained in their IPAPs with NATO or bilateral arrangements with the U.S.

In coordination with the PfP Consortium of Defence Academies and Security Studies Institutes, the Partnership Training and Education Centers, the George C. Marshall Center and the Bureau for International Language Coordination as well as with specific allied and partner defence education institutions, NATO is leading or supporting eight tailored DEEPs [5]. Since 2007, NATO has conducted DEEPs with Armenia, Azerbaijan, and Georgia. The PfP Consortium of Defence Academies and Security Institutes (PfPC) has played a leading role in bringing together allies and partners to develop and execute DEEPs. These programmes, which are tailored to meet individual partner requirements, provide opportunities for the PfP partners to develop both their defence education curricula and faculty. Good curricula would also contribute to understanding the holistic nature of professional military education, the hierarchy of schools that lead from Cadet to Colonel [3]. Not only do these programs provide an effective way to transform national security establishments and enhance the security capabilities of partners, they also do so in a way that does not provoke neighboring nations. In the case of the countries fraught with frozen conflict, it may be the best means to avoid the region becoming a "shatter zone" along the rim land, and "marginal areas" to Mackinder's pivot and heartland thesis - a prominent line of thought in NATO as it wrestles with security challenges and opportunities in the region [13]. The United States, working in close cooperation with North Atlantic Treaty Organization (NATO) headquarters, has signaled the importance of defence education in its engagement with a number of former Soviet Union states and NATO partner nations of interest through the creation of the DEEP [20].

DEEP facilitates (or provides the opportunity to incorporate) the incorporation of Western or modern norms and methods in the field of PME for officers and NCOs while preserving host nation prerogatives as independent States, as well as ensuring ownership of the outcome [14].

\section{The South Caucasus and DEEP}

As the South Caucasus partners look to better understand Western "ways of thinking" and develop their own national security professional, they have turned to NATO allies and other partners for PME support. Establishing effective PME programs conducive to creative problem solving requires senior military leader investment [22]. 
If they want their military professionals to be more adaptive and agile in both thought and action while they face unpredictable and complex security environment, they should invest in education. The role of PME is to provide the education needed to complement individual training, operational experience and self-development to produce the most professionally competent individuals possible [15]. For mid-level military professionals is often viewed as a time to study broad perspectives and think about diverse strategies in hopes of fostering innovation. Merely attending courses removed from the operational force, however, is not enough, and operational commanders must proactively invest their own time and perspectives to actively support education [22]. For the time being NATO is the best entity possessing this experience and capacity. All countries from the South Caucasus region are engaged in discussions with NATO on PME topics of interest through both bilateral and multilateral DEEPs. The DEEP initiative provides an alternative to sending partner officers, NCOs, and civilians to courses abroad and thus makes defence education more accessible to a larger number of participants [13].

NATO support for defence education is defined in the EAPC document, "Implementing the PAP-DIB: The Education and Training for Defence Reform Initiative - Guidelines for Development". It has been reconfirmed by the Berlin decisions on partnerships and discussions at the 2012 Chicago Summit that identified the need for the further development of partner capacity through defence education. Through the adoption of the "Policy for a more efficient and Flexible Partnership" in Berlin in 2011, NATO member states committed themselves to offering enhanced support to interested partners in order to develop their defence education and training capacities [5]. Thus, PME system offers remarkable opportunity for officers at various stages of their carrier, to take time out from their normal job, gain exposure to national security issues and interact with others from different branches of the Government [15]. By 2012, the participants in the DEEP process, led by the NATO International Staff, became convinced that a functional clearing-house for defence education would be required to facilitate the identification of these subject matter experts in curriculum and faculty development [5]. The first donors' functional clearing-house on defence education took place on 13-14 September 2012 in Brussels. It was designed to serve as a forum to inform institutions and countries about the DEEP initiatives that NATO conducts in partnership with interested states. The clearing-house also created a coordinated effort for allies and partners to align the defence education requirements contained in their partner cooperation plans with the defence education institutions within NATO that are most capable and appropriate to support these specific needs. Approximately sixty personnel, representing thirty-seven defence education institutions and NATO staff elements, drawn from twenty-two allied and partner nations, participated in the two-day session [5]. The substantive focus for the clearinghouse would be on the identification of how to support the PME needs of partners. This would include emphasis on [5]:

- development of curricula (what to teach);

- development of a defence education programme specifically designed for faculty (how to teach); 
- ensuring that the DEEPs are developed to meet the requirements/needs of partners;

- advising partners on how to develop their defence education programs as they evolve.

In 2014, The Defence Capacity Building Initiative was launched at the Wales Summit, with DEEP as a supporting element [6]. Designed to strengthen the Alliance's contribution to international security, stability and conflict prevention, DCB reinforces NATO's commitment to partners with assistance beyond what is offered through existing programmes. The Initiative builds on NATO's extensive expertise in providing advice, assistance, support, training, education and mentoring activities in the defence and related security sector [21]. Georgia is only country in the region benefiting from DCB package. In order to shed light on this initiative it would be better to lay out the DCB package offered to Georgia. Georgia's DCB package is provided through the Substantial NATO-Georgia Package. The package includes: establishing three facilities (a Joint Training and Evaluation Centre, a Defence Institution Building School and a Logistic Facility) as well as providing expert advice in the areas of acquisition, strategic and operational plans, Special Operations Forces, military police, cyber defence, maritime security, aviation, air defence, and strategic communications. The package also includes support and contributions to NATO exercises in Georgia that are open to partners. Several projects were launched under this initiative [21]. Based on its needs, iti is not difficult to imagine how much Georgia has benefited from this initiative. The establishment of facilities directly contribute to the development of PME in Georgia.

In 2016, at the Warsaw Summit, Allied leaders decided to enhance NATO's role in projecting stability beyond NATO's borders, including through defence education and reform [6].

The DEEP has grown exponentially since its inception and so have the number of activities. The demand is indicative of a desire for change, but this does not translate directly into programme success. While demand is normally associated with programme growth it is far from guaranteed that the financial commitment will always be present to meet the needs expressed by host nations [14]. It is a remarkable feature of the DEEPs that the work is done by volunteers, is supported by volunteer institutions, and is endorsed by volunteer nations. NATO's contributions through the influence of the IPAP, the public recognition NATO gives to both defence education reforms in partner countries and the support provided by allies, its coordinating role in scheduling events and recruiting educators from NATO nations, and those talented educators themselves all converge to enable the programme to advance [3]. Each DEEP strives to respond to validated, demand-driven requirements from the host nation and not on supply-driven availability of subject matter experts. At the same time, the DEEP endeavours through dialogue and encouragement to influence supported educators in the direction of the following objectives [19]:

- guide and mentor reforms in professional and military education, both in individual defence education institutions and in a defencewide holistic approach to PME;

- promote learner-centred education to support critical thinking skills and innovative use of instructional technologies; 
- encourage and enable the use of learning objectives which facilitate a depth of learning that can be readily applied through practice and experience;

- assist in the development of curricula where these methods can be employed in support of partner goals contained in their Individual Partnership Action Plans with NATO or bilateral arrangements with the U.S.

Since DEEPs are tailored to meet individual partner needs, they also provide the South Caucasus nations with the opportunity to self-differentiate in both their assistance requests and in the level of cooperation, they desire with NATO on PME issues. DEEP initiatives to date have responded to a variety of requests for assistance, including developing course modules, establishing a Command and General Staff College, starting up research institutions and offering faculty "shadow" programs, to name a few: In order to establish a DEEP, NATO sends a visiting team of subjectmatter experts to the partner country for approximately one week to discuss partner needs, priorities and objectives for future education reform. These Curriculum and Teaching Development Teams (CTDTs) are composed of subject-matter experts who are both academics (teachers) and practitioner with recent field experience, as well as those who are knowledgeable on the countries and their sensitivities [13]. A central factor to a successful DEEP initiative is the dedication shown by Euro-Atlantic educator who volunteer their (and their institution's) time to share their expertise and knowledge. They primarily come from military, academic and security studies institutions in the United States, such as the Army War College, the Naval War College, and the National Defence University, as well as from PME institutions in countries such as Austria, Bulgaria, Canada, the Czech Republic, Germany, Italy, Poland, and Romania, Slovakia and Switzerland [14]. On their side, the partner country identifies future instructors, heads of existing military institutes/training departments and others involved in education reform who will be instrumental to the change process. The partner also provides opportunities to meet with political and military leadership in order to ensure that support for education reform is gained and maintained at the highest levels. By including education and training as a priority in their NATO documents, the partner state also signals to NATO the importance they are placing on reform in this functional area [13]. Undoubtedly, these tailor-made programs have been successful, but there is a need to institutionalize the entire process. The clearing-house is the means to do this, especially as it becomes critical to recruit more and more experts because of the increasing demand for DEEPs. In all likelihood, the programs will continue to grow as defence education institutions become more sophisticated and as the requests for more events and programs increase, thus requiring more and more contributions of support [5].

According to, Alan Stolberg, coordinator of the PfP Consortium, there are three main functions in DEEP: help provided for the partners, transferring suitable teaching methods, and supporting education institutions in becoming successful [4]. In retrospect, all these functions have successfully worked. The partners have demonstrated progress at each annual review and have asked to extend their DEEPs. In every country, they have added new levels of professional military education. Course structures and content increasingly reflect the influence of this initiative. New learning methods are in place. The Consortium works in close and productive partnership with 
NATO, where each partner nation's IPAP provides top-down direction for the commitment to change [3].

Once a baseline is set and an Action Plan has been agreed upon between NATO and the partner (or bilaterally), the CTDT makes repeat visits to the country to assist both curricula and faculty development as needed. In some cases, this means that the team co-teaches course for a couple of days with the host-nation assumes the primary role. The CTDT remains ready to assist or provide additional information on an as needed basis. Depending on a country's needs and the availability of allies and NATO to support programme implementation, the CTDT teams may be conducted on a multinational or bilateral basis. A NATO representative may also be involved in crafting the Action Plan (in accordance with NATO agreements, such as IPAPs) and/or the NATO Liaison Officer (LO) in the region may play a role. The NATO LO may be active in crafting the plan, executing the CTDT, and consulting with the partner between visits to ensure that the process is moving forward as scheduled [13]. The requesting country will have the opportunity to send members of its teaching staff on "Shadow Faculty" visits to other military education institutions [14]. To ensure support from all sides, the DEEP PME Action Plans are also briefed at NATO Headquarters in the PPC [13]. DEEP programme also includes deployment of Mobile Education Training Teams (METTs), which could be useful tools for promoting the regional dimension of defence education and increasing the number of students [9]. Throughout this process, students and institutions are transformed towards the goals of education institution modernization and interoperability with NATO. For instance, in Kazakhstan, the educators' workshops have been so successful that the Kazakh NDU has the ability to sustain its own faculty development programs; a clear sign of successful adaptation [14].

Integrated PME programmes provide an opportunity to replicate the projects that the cadets/officers at leading NATO military institutions carry out. DEEP enables the South Caucasus nations to invest their time and resources properly. Most importantly, lessons learned from the staff with academic and field experience will get passed down to future military professionals through blended experiences. As Frédéric Labarre and Pierre Jolicoeur suggested: "Reciprocity is essential to any effective and dynamic partnership. When host nations start providing DEEP initiatives with content or newlyacquired skills, they cease to be consumers of the program, and become contributors. Such an outcome multiplies the strength and reach of the program, and shows that Euro-Atlantic values and principles are harmonized" [14].

NATO as an organization is apt to become attuned to more complex, rapidly evolving, and increasingly unpredictable security environment. It makes the Alliance more attractive. For instance, Wales Summit Declaration highlights Alliance's members commitment to developing cyber defence capabilities and their vision of integrating cyber defence into NATO operations and operational/contingency planning, as well as their pledge of improving the level of cyber defence education, training, and exercise activities through NATO training and education bodies. Partnerships were underscored to be essential to the way NATO works [23]. At the Warsaw Summit, Allies agreed that enhancing the cyber defences of national networks and infrastructure had become a matter of priority. One of seven main objectives the 
Allies pledged to pursue was once again as fostering of cyber education, training, and exercises it was underscored at Wales Summit [24]. 20 Allies and 2 partner countries are participating in cyber defence Smart Defence projects. 19 partners have Individual Partnership and Cooperation Programmes with an integrated cyber component. 16 partners have cyber defence integrated into partnership plans [21]. DEEP was pronounced once again to be a tool to build defence capacity and interoperability [24]. This approach in its turn prompted the South Caucasus countries like any other partner nations to get closer to the Alliance.

DEEP stands out as one of the major reasons why NATO has remained a relevant international actor into the $21^{\text {st }}$ century. Collective education and training has been ongoing since the inception of the Alliance in 1949, but never to this extent. If NATO continues to develop DEEP and expand its functions to new places then it could well end up becoming the primary force for regional stability in the world. It is often overlooked or forgotten, but institutional change must come from within a country rather than be exported from other places. DEEP does well in providing assistance to shape the defence institutions of a developing country and has aided NATO in remaining a relevant, international actor [25]. Thus, the implementation of DEEP by the South Caucasus countries helps them to produce positive changes in the region, in spite of the existing challenges. NATO should remain committed to encourage them to achieve incremental progress in promoting transformational projects regarding their PME. At the same time, the NATO DEEP ADL Portal is available, and it creates a compendium of expertise in the use and implementation of new technologies in defence education and training [7]. It is of importance while considering the developments within security environment [8].

\section{Conclusions}

The South-Caucasus countries have been endeavouring for decades to upgrade their professional military education. There are two competing blocs which offer different tools: NATO and CSTO. Azerbaijan and Georgia rule out cooperation with CSTO, where Armenia is its member state. However, all three countries cooperate with NATO even though they do not implement its tools with the same intensity. The integration of the region into NATO is a political issue, which in its turn creates obstacles for particular nations. However, utilizing DEEP in pursuit of peace and prosperity in the region is professional and non-political, which does not endanger the relations with neighbor countries and should not antagonize them. Potential areas of cooperation, like preparation of junior and senior officers, improvement of professional $\mathrm{NCO}$ system, distance learning, curriculum development at master and PhD levels, exchange of academic experience based on this programme contribute to peace and security all three nations are concerned with. The enhancement of the cooperation within this programme will enable the security institutions in the South Caucasus region, which were inherited from the soviet era to be completely transformed over the next years. The active implementation of NATO's DEEP programme by the countries in the South Caucasus significantly affects the integration process of the whole region 
which is struggling to catch up with the Western (at least Central and Eastern European) countries regardless of different obstacles.

\section{References}

1. Annual Report 2012, PfP Consortium of Defence Academies and Security Studies Institutes, Vienna and Garmisch-Partenkirchen, March 11, 2013, https://bit.ly/21MOOLU.

2. Annual summary of the NATO DEEP programme, Tuesday, July 02, 2019, https://bit.ly/2lL2iaG.

3. Berry, John, "Defense Education Enhancement Program: The Consortium Perspective", Connections: The Quarterly Journal 11, no. 4 (2012): 27-33.

4. Constant Learning: the Essence of NATO, Jun 20, 2019, https://bit.ly/21FbNbG.

5. D'andurain, Jean and Alan G.Stolberg, "Defense Education Enhancement Program: The NATO Functional Clearing-House on Defense Education", Connections Vol. 11, No. 4 (Fall 2012): 53-58, https://bit.ly/2k7vkRt.

6. Defense Education Enhancement Programme (DEEP), Last updated: March 05, 2019, https://bit.ly/2wBdQSU.

7. Gawliczek Piotr, Innovative ICT solutions and/within/for changing security environment. Case study - NATO DEEP ADL Portal and Social Media, "Social development Security", Vol. 9, No. 4, 2019. DOI: https://doi.org/10.33445/sds.2019.9.4.8

8. Gawliczek Piotr, Security Environment Perceived from Innovative Information/Communications Technology and Social Media Perspective. Towards System Solutions, in: Security and Russia Threats, ed. M. Banasik, P. Gawliczek, A. Rogozińska, Uniwersytet Jana Kochanowskiego w Kielcach, 2019.

9. Ignjatijevic, Marija, How can NATO cooperation in the field of training contribute to regional and education? (Belgrade Centre for Security Policy, 2019), Mar 17, 2019, https://bit.ly/2mdGVPM.

10. Iskandarov, Khayal, The South Caucasus - NATO cooperation, (Lambert Academic Publishing, 2019).

11. Iskandarov, Khayal, Elman, Nasirov The prospects of Azerbaijan to enhance military interoperability with NATO, Connections QJ 16, no. 4 (2017): 91-101.

12. Kaim, Markus, "Reforming NATO's Partnerships", SWP Research Paper, Stiftung Wissenschaft und Politik German Institute for International and Security Affairs, Berlin, January 2017, https://bit.ly/2komnUa.

13. Keagle, James, Tiffany Petros, "Building partner capacity through education: NATO engagement with the Partnership for Peace", Connections: The Quarterly Journal 10, no. 1 (2010): 46-63.

14. Labarre, Frédéric \&Pierre Jolicoeur, "Shaping and measuring military culture development: a case study of the defense education enhancement program", Canadian Foreign Policy Journal, Volume 22, Issue 2 (2016): 135-146, https://bit.ly/2kddfSg.

15. Mallick, PK, Professional Military Education-An Indian Experience, New Delhi: Krish Printers, September 8, 2017, https://bit.ly/2mbQn64.

16. Nasirov, Elman, Khayal Iskandarov, The prospects of Azerbaijan to enhance military interoperability with NATO, Connections QJ 16, no. 4 (2017): 91-101.

17. "National styles of professional military education", PME Investigation Paper No 2 (June 2017), https://bit.ly/2ml30vR.

18. NATO Allies underscore Defence Education Enhancement Program, September 18, 2014, https://bit.ly/2kBVg8a.

19. Stolberg, Alan, "Education Development Working Group" in Annual Report 2013 / Ernst M. Felberbauer, Enrico Müller (Eds.), PfP Consortium of Defence Academies and Security Studies Institutes, 5/2014, Vienna and Garmisch-Partenkirchen, March 20, 2014, https://bit.ly/2lEuqfV.

20. Stolberg, Alan G., Stuart Johnson, Laura Kupe, "Building Partner-Nation Capacity through the Defence Education Enhancement Program”, Jan 31, 2018, https://bit.ly/2rn7Fg3. 
21. The Secretary General's Annual Report 2015, Jan 7, 2016, https://bit.ly/2z5xTZW.

22. Tran, Thang, Michael Oliveira, Josh Sider, and Leo Blanken, "Ignorance and professional military education: The case for operational engagement", November 7, 2018, https://bit.ly/2yTxx7i.

23. Wales Summit Declaration, 05 Sep. 2014, Last updated: 30 Aug. 2018, https://bit.ly/2QFyWVS.

24. Warsaw Summit Declaration, 09 Jul. 2016, Last updated: 29 Mar. 2017, https://bit.ly/2hI5I96.

25. Willschick, Aaron, "In too "DEEP". NATO as an institutional educator", February 22, 2013, https://bit.ly/2m9fGG9.

(C) 2019 by the authors; Social development \& Security, Ukrainian. This is an open access article distributed under the terms and conditions of the Creative Commons Attribution (CCBY) license (http://creativecommons.org/licenses/by/4.0/). 